\title{
Transforming brand core values into perceived quality: a Volvo case study
}

\section{Kostas Stylidis*}

Department of Industrial and Materials Science,

Chalmers University of Technology,

412 96, Göteborg, Sweden

Email: stylidis@chalmers.se

*Corresponding author

\section{Steven Hoffenson}

School of Systems and Enterprises,

Stevens Institute of Technology,

NJ 07030, Hoboken, USA

Email: shoffens@stevens.edu

\section{Monica Rossi}

Department of Management, Economics and Industrial Engineering,

Polytechnic University of Milan,

201 56, Milan, Italy

Email: monica.rossi@polimi.it

\section{Casper Wickman}

Department of Industrial and Materials Science,

Chalmers University of Technology,

412 96, Göteborg, Sweden

and

Volvo Car Group, Craftsmanship \& Ergonomics Centre,

91300 PVÖS35, 405 31,

Göteborg, Sweden

Email: casper.wickman@volvocars.com

\section{Mikael Söderman}

Advanced Technology \& Research,

Volvo Group Trucks Technology,

BF 40630, M1, 405 08,

Göteborg, Sweden

Email: mikael.soderman@volvo.com 


\section{Rikard Söderberg}

Department of Industrial and Materials Science, Chalmers University of Technology,

412 96, Göteborg, Sweden

Email: rikard.soderberg@chalmers.se

Abstract: Core values are an important part of Volvo Car Group's and Volvo Trucks' strategic development plans. These two companies share the same core values, quality, safety, and environmental care, but they approach these values in different ways. This study seeks to understand how industry professionals and customers perceive these core values and the attributes that are associated with them, using semi-structured interviews with industry professionals from both companies and quantitative survey methods with customers. The purposes of this study are to investigate how designers convey core values to customers through product attributes and how customers perceive those core values through the same attributes. Such an understanding reveals the commonalities and discrepancies between the perspectives of producers and customers, and can contribute to more effective design processes that communicate company values in the early product development phases.

Keywords: automotive design; product development; communication; perceived quality; core values.

Reference to this paper should be made as follows: Stylidis, K., Hoffenson, S., Rossi, M., Wickman, C., Söderman, M. and Söderberg, R. (2020) 'Transforming brand core values into perceived quality: a Volvo case study', Int. J. Product Development, Vol. 24, No. 1, pp.43-67.

Biographical notes: Kostas Stylidis is a Researcher at Chalmers University. His primary research interest is the perceived quality of the cars. He focuses on the premium and luxury segment of the automotive industry.

Steven Hoffenson is an Assistant Professor in the School of Systems and Enterprises at the Stevens Institute of Technology. His research brings systems thinking into interdisciplinary approaches to design, with an emphasis on sustainability. This combines engineering models, decision theory models, economic models, and a systems framework to build an understanding of how different decisions with respect to product development and adoption will affect the economic, environmental, and social sustainability of the surrounding world.

Monica Rossi is an Assistant Professor at Politecnico di Milano in the Department of Management, Economics and Industrial Engineering.

Casper Wickman is a part of the Research Group Geometry Assurance \& Robust Design at the Department of Industrial and Materials Science. He is also holds a position as Technical Leader within the area of Craftsmanship and Ergonomics at Volvo Cars. He is also a Theme Leader for Perceived Quality in VINNEX phase III at Winquist Laboratory. The research is conducted in collaboration with both Volvo cars and Volvo AB.

Mikael Söderman is a Project Manager at Volvo Group Trucks Technology, Advanced Technology \& Research. 
Rikard Söderberg is a Chair Professor in Product and Production Development. He received his $\mathrm{PhD}$ from Chalmers in 1995. After some years in the IT and consultancy sector he went back to Chalmers to build up his research group within Geometry Assurance and Robust Design. He was head of department for Department of Product and Production Development until 2017 when Chalmers reorganised and he is a Director for Wingquist Laboratory.

This paper is a revised and expanded version of papers entitled 'Corporate and Customer Understanding of Core Values Regarding Perceived Quality: Case Studies on Volvo Car Group and Volvo Group Truck Technology' presented at the '24th CIRP Design Conference, Milan, Italy, 2014; and 'Perceived Quality and the Core Values in the Automotive Industry: A Corporate View' presented at the '3rd International Conference on Design Creativity', Indian Institute of Science, Bangalore, India, 2015

\section{Introduction}

The automotive industry today is characterised by a high level of competitiveness, which among other factors has an impact on future car performance, features, and appearance. The major manufacturers in the premium segment already have strict manufacturing quality control (Robinson, 2000), so providing customers with a well-built vehicle is considered a given and therefore not an area in which manufacturers can compete for more market share. Thus, in the premium segment, automobile manufacturers seek an advantage over their competitors by producing vehicles that customers perceive as "high quality", regardless of the minor differences in build quality. Corporate brand heritage, linked to customer perceptions of corporate image and core values, can play a significant role in communicating product and brand characteristics with customers (Rindell et al., 2015; Urde et al., 2007). Brand heritage and core values represent a company's beliefs and character, and they are generally expressed by the companies through the physical design of products that consumers can then perceive and evaluate to make purchase decisions.

Volvo as a brand has a long tradition of three major core values (quality, safety, and environmental care). These core values form the foundation of the brand (Urde, 2009). Design processes that seek to address perceived quality and represent core values are driven by a set of requirements that the final product must fulfil. This is challenging because the evaluation of perceived quality attributes is often subjective and intuitive rather than objective (Eckert et al., 2014). In design research the identification of, and ability to evaluate, product attributes related to perceived quality are ongoing challenges (Burnap et al., 2015; Yumer et al., 2015). However, there is evidence that insufficient methodological support causes industry to employ intuitive rather than strategic or systematic communication practices (Liem et al., 2009). Sometimes this approach can be successful, due to the company's accumulated expertise and heritage, but in many cases it is detrimental to the product's success on the market. Therefore, the automotive industry has a continuous demand for objective and systematic methods and tools that will allow the definition and validation of perceived quality-related requirements for complete vehicles or their parts (Huertas-Leyva et al., 2011). A stronger understanding of how core values are communicated with customers would significantly contribute to the development of such methods. 
At the same time, understanding how customers perceive product quality and comparing that with the viewpoints of industry professionals could highlight critical discrepancies between designers and users. Such discrepancies can result in ineffective communication of the corporate brand core values that can be traced to the company's physical products and product development process (Urde, 2009). This study looks at the cases of Volvo Car Group (VCG) and Volvo Trucks (VT), two separate companies that share the same brand heritage and core values but approach these in different ways due to different customer demands. The study investigates how the companies communicate their corporate core values to their customers, and which particular vehicle attributes the companies use to represent those values. The article also reveals current trends regarding communication of core values and perceived quality. The objectives of the present study are to elicit how industry professionals and customers each perceive the core values and the attributes that are associated with them, and to provide a new systematic approach that companies can use to determine attributes and the existing discrepancies between viewpoints. Two different companies under the Volvo brand are used to showcase the versatility of the approach and demonstrate how the same core values can be communicated in different ways.

In-depth qualitative interviews were performed with senior management personnel, key people from both companies who define development and the future looks and attributes of VCG and VT vehicles. To understand how these core values are perceived by customers in practice, a quantitative survey was conducted with a number of Volvo car owners, as well as with semi-trailer truck drivers. The respondents were given online tasks to rank the importance of the attributes that were listed by the professionals, providing an understanding of some of the similarities and differences between the ways that designers/engineers and users perceive Volvo's shared core values. One of the methods used in the surveys was Maximum Difference Scaling (MaxDiff), which is a quantitative choice-based technique used for understanding a respondent's or a respondent group's relative valuation of different products or product attributes (Louviere, 1993). MaxDiff is used along with semantic-differential scale questions. This helps to detect lack of discrimination and confounding among respondents (Magidson et al., 2009).

This article begins with a discussion of the background theory behind the approach and the research methods. This is followed by a description of the methods used to interview the design professionals and a summary of findings, as well as the same for the customer surveys. It concludes with a discussion of the results and suggestions for further research.

\section{Background and methodology}

Historically Volvo is a heritage brand with an established corporate track record. However, despite the notion that heritage brands "are stable reference points in a changing world" and assertions that "customers value heritage" (Balmer, 2013), the process of communicating brand core values can be ambiguous for brand management.

In the recent past, industry professionals operated with simple brand structures, few sub-brands, and straightforward business strategies. Today, the situation has changed dramatically, as brands have become more complex, the business environment has grown more difficult to navigate, and challenges are now reaching a global level (Aaker and 
Joachimsthaler, 2000). In order to translate brand core values and successfully transfer these to the customer, there is a need to create a strong identity and express this identity by consistently managing relevant "touchpoints" with customers. These include awareness, associations, attitude, attachment, and activity (Keller and Lehmann, 2003). In the premium segment of the automotive industry, the company communicates many of these touchpoints with the customer through perceived quality attributes, such as craftsmanship, surface finish, and split lines. Perceived quality also involves many aspects of customer cognition and product properties, including emotions, aesthetics, semiotics and semantics, and gestalt perception of the design. Therefore, perceived quality can be determined differently by different manufacturers. Vehicle manufacturers are continuously looking for improvements in their communication strategies to minimise the gap between designer intentions and customer expectations. This is not an easy task because there is often no direct contact between designers and customers. In fact, engineers often have incomplete information regarding the customer's sensory perception of the attributes related to perceived quality (Striegel and Zielinski, 2018). One of the crucial procedures for defining customer requirements is the benchmarking of a new product against competitors, usually from the same market segment. However, previous studies (Stylidis et al., 2016) have identified possible bias in the premium automotive segment regarding this procedure. Since there are a limited number of players in the premium segment, with limited information regarding competitors, the chance of incorrect importance estimation for product attributes is high. In this case the benchmarking process can be detrimental to a product's success on the market.

One of the theoretical frameworks explaining these communication discrepancies is information asymmetry. In this context, information asymmetry is caused by misinformation due to existing differences in background knowledge of, and available information to, the designer and customer (Christozov et al., 2009). Information asymmetry works both ways. For example, from a designer perspective, limited knowledge about customer preferences and values can result from a time-critical development processes. From a customer perspective, information asymmetry can be caused by the limited communication capacities of products and various human factors, including different epistemologies during observation and interpretation (Krippendorff, 2009). Information asymmetry can also appear if the actual quality of the product is not apparent due to its complexity, which is a common phenomenon in modern vehicles. Generally speaking, information asymmetries are naturally related to any process of information exchange and create a risk of misinterpretation and miscommunication (Christozov et al., 2009). Engineers must strike a balance in representation of perceived quality attributes that convey core values, while ensuring that the car is perceived by customers as having high quality. At the same time, customers often have difficulty expressing their opinions about a product with a high level of complexity, such as a premium vehicle. Information asymmetry can significantly influence the interpretation of core values through perceived quality and it should therefore be minimised during the communication process to avoid an information imbalance between designers and customers.

\subsection{Communication model}

Many conceptualisations of communication rely on codes. These are conventions for communication, to convey the intended meaning to the receiver. In design research it has 
become evident that the focus should be placed on the interpretation of the product by users (Crilly et al., 2008). According to Vihma's (1995) semiotics approach, customers see a final product as a number of signs to be interpreted. Krippendorff and Butter (1984) suggested that a designer plays the role of a communicator, creating a range of forms, and it is useful to view his or her relationship with the customer as part of the communication process. Shannon (1948a, 1948b) developed a basic communication system containing such elements as the information source, transmitter, channel, receiver, and destination. The information source communicates different types of messages to the destination. A transmitter produces a signal suitable for the channel, and the encoded signal is then transferred over the channel. The receiver then decodes the signal and recreates the message designed for the destination. This model in general greatly influenced communication theory (Beniger, 1990).

Forslund and Söderberg (2007), drawing on Shannon's communication model with additional input from Crilly et al. (2004), as well as Krippendorff (1986), summarised a process of communication as customer awareness and perception of the message deriving from the designer. Thus, product features are transferred across the channel of the final product. These features are then decoded by the senses (vision, touch, smell, and hearing) and subsequently perceived by the customer. Communication of the brand core values can be viewed with the same approach.

In this study, the described communication model is implemented in regard to the transmission and interpretation of core values through perceived quality. Qualitative interviews with senior and top management of VCG and VT were used to record their visions and interpretations of the company's core values. These semi-structured interviews also investigated product attributes that, in the opinions of those interviewed, represent the core values.

Crilly et al. (2004), drawing on O'Shaughnessy (1992) and Bloch (1995), describe a traditional view of customer perception of the product as a form of "cognition and affect followed by behaviour". The present approach represents a communication system for core values transfer, developed as an adaptation of the design communication process characterised by Crilly et al. (2004), which states that "designers have intentions for how a product should appear, the product is manufactured, placed in an environment, perceived by the consumer and finally responded to" (see Figure 1).

Figure 1 Basic framework for design as the process of communication, adapted from Crilly et al. (2004)

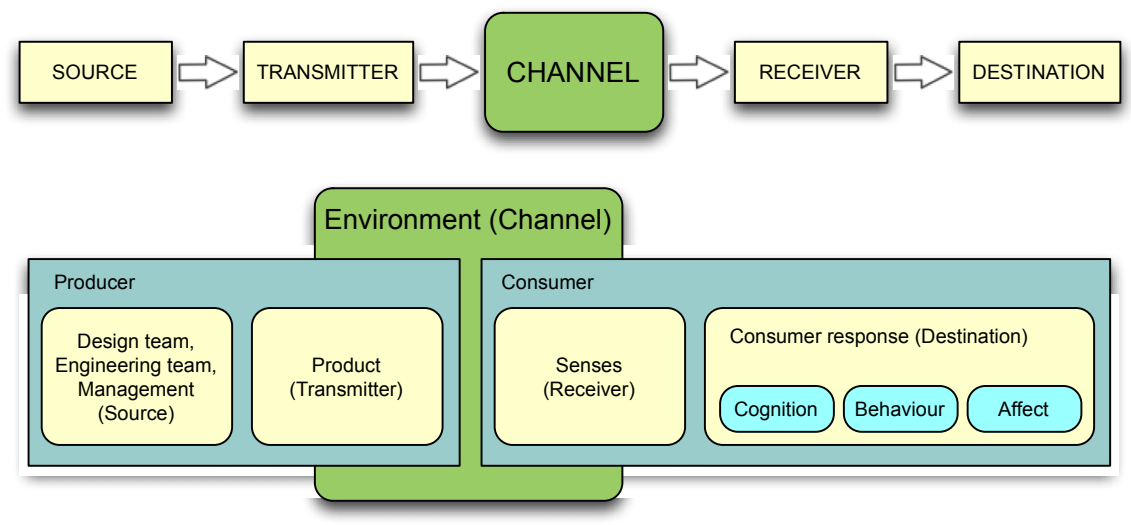


This article examines how the core values of VCG and VT are reflected through product quality attributes, seeing them as both the source and the transmitter. This is accomplished using a combination of exploratory research methods to understand producer and consumer perceptions in this communication model.

\subsection{Challenges for the premium segment of the automotive industry}

From a communication theory perspective, brands and their products are expressed by a number of cues or attributes. In the case of the premium segment of the automotive industry these attributes signal quality and provide functional, value, and hedonic benefits to the customer. The immediate problem that appears is the evaluation of the perceived quality attributes by designers and engineers regarding their conformance to the customer requirements. This process is challenging, mainly because of the subjective nature of some attributes, a lack of the robust methods for capturing and translating the voice of the customer into technical requirements, and the intuitive approach often taken by designers (Eckert et al., 2014). Moreover, customers often find it difficult to express their opinions about a product with a high level of complexity, such as a premium vehicle. Given these points, designers and engineers need to strike a balance in representing brand design attributes while ensuring that the product is perceived by customers as having high quality.

For example, appearance is an essential product characteristic that is assessed subjectively by both designers and customers. Muller (2001) analysed different flows of aesthetic appreciation theory, including numerical aesthetics, minimalist aesthetics, psychological aesthetics and semantic aesthetics. These flows provide different viewpoints regarding aesthetics, and the present study reveals, among other things, a trend toward simplifying complex technical systems when presenting them to the customer. Implementation of such a strategy can lead to underestimation and misjudgement of the final product by the customer. Berlyne's (1974) theory, first developed in 1960, states that optimal complexity exists and is defined as a complexity that is most attractive to the customer. Extreme complexity at the high end of the spectrum is perceived as being less attractive (see Figure 2).

Figure 2 The relationship between perceived complexity and the degree of attractiveness according to Berlyne (1974) and Muller (2001), adapted from Warell (2003)

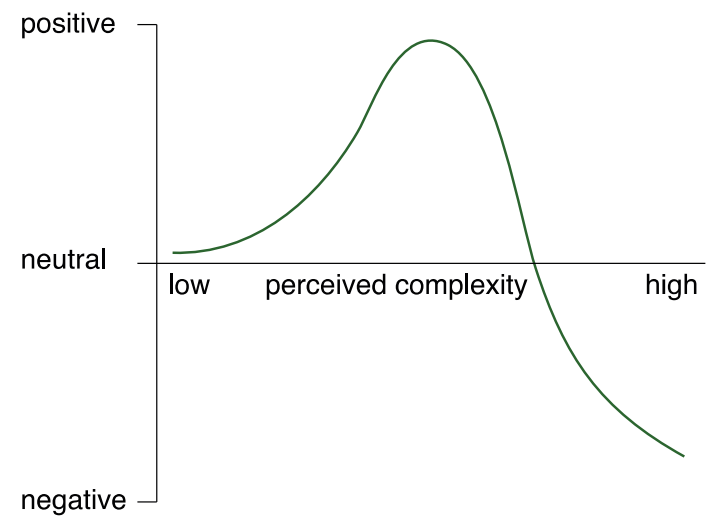


Balancing the complexity of design cues that represent product quality is not the only challenge for the automotive industry. With its historically developed excellence in manufacturing quality, the premium automobile market segment now exhibits product differentiation largely dependent on customer emotional responses to the particular design (Norman, 2013; Schmitt and Quattelbaum, 2009). Identification of the attributes linked to perceived quality and emotional design is an ongoing challenge in engineering research and practice (Burnap et al., 2015); with a number of established and developing methodologies, such as Kansei Engineering. Kansei affective engineering is a set of methods that translate the subjective emotional response of the customer to the product's attributes and characteristics (Nagamachi, 2002). Despite these useful tools for understanding subjective product attributes, implementation of these processes is implicit, time-consuming, and may not provide an adequate evaluation of subjective product features and attributes (Eckert et al., 2014).

Another important aspect related to perceived quality is the phenomenon of gestalt in design. Gestalt was initially studied by Austrian and German psychologists in the late 19th century when they established the research field of "gestalt psychology." Koffka (1935) defined this principle as "the whole is 'other' than the sum of its parts." Monö et al. (1997) defined product gestalt as "a discernible whole; an arrangement of parts so that they appear and function as a whole which is more than the sum of parts". This supports the idea that perceived quality attributes are not present as entirely isolated factors, but that they influence one another. Thus, setting requirements for perceived quality is a multidimensional task, and research is needed to establish methodologies to measure such attribute relationships objectively.

\subsection{Exploratory research methods}

Interview studies are typically classified as structured, unstructured or semi-structured. Semi-structured interviews that include structured and unstructured elements were used in this study to understand the viewpoints of automotive industry professionals. According to Cachia and Millward (2011), semi-structured interviews follow a predetermined set of questions, as in structured interviews, while allowing "additional questions... to facilitate further exploration of issues brought up by the interviewee," as in unstructured interviews.

To evaluate the customer side of the communication model in Figure 1, preference information needed to be collected and analysed from a diverse set of customers regarding a large number of attributes. One method for acquiring ordinal preferences without overloading respondents with overly challenging tasks is maximum-difference scaling (MaxDiff). MaxDiff offers respondents a series of "best-worst" tasks, where they choose the "best" and "worst" option from a list of 4-7 alternatives. This method was originally developed by Louviere (1993) to understand a respondent's or respondent group's relative valuations of different products or product attributes. The main purpose of this method is to aggregate and estimate rank-order information when there are too many attributes for a normal rank-order survey task. According to Marley and Louviere (2005), best-worst tasks positively affect the consistency of the responses and can be easily understood by respondents. One limitation of MaxDiff is that it can only provide ordinal information, for example that one attribute is more important than another, without providing any absolute information, for instance regarding whether either of those attributes are even significant influencers in the decision-making process (Orme, 
2005). Therefore, the MaxDiff tasks are combined with a small number of semanticdifferential tasks that ask for the perceived importance level of specific attributes, ranging from not at all important to the highest priority of importance. A benefit of this combined approach over pure semantic differential questioning is that the latter option often suffers from a lack of discrimination (Magidson et al., 2009). In other words, some respondents will rate a plurality of the attributes as important and be distracted by the scale, and some respondents will choose extreme values more than others.

The study procedure was first a series of in-depth, semi-structured interviews with professionals to discover the key design attributes intended to influence perceived quality, followed by a survey performed by drivers to understand the importance of those attributes to the customers (see Figure 3). These were done separately but concurrently for the VCG and VT applications.

Figure 3 Scheme of the case study procedure

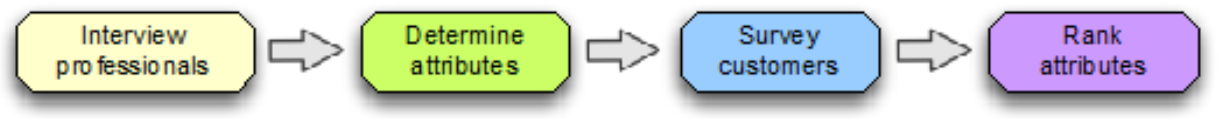

\section{Professional study}

The first task was to perform a qualitative study on automotive industry professionals from VCG and VT to reveal a list of product attributes that represent the three core values of quality, safety, and environmental care. This list of perceived quality attributes was then used in the development of two different surveys that were performed by car and truck drivers.

\subsection{Interview design}

The semi-structured interview study involved six high-ranking professionals within VCG and VT at the levels of director and vice president. Their responsibilities include areas of perceived quality, product marketing, complete vehicle requirements definition, environment, branding, and strategy management. All of the respondents have long track records in the automotive industry and working experience in different markets, both in Sweden and abroad. The main reason for the selection of interviewees was to obtain a holistic view regarding the core values communication processes in the companies, and perceived quality. Each of the interviews was completed face-to-face in approximately 40-60 minutes. The set of questions was developed to clearly reveal the respondents' visions of the core values, explain communication strategies, and show how they understand and implement core values, particularly regarding perceived quality. Professionals from VCG and VT were asked the same types of questions, since they share the same core values. At the beginning of the interviews, questions were relatively open and general, for example:

- Could you describe your responsibilities at the company?

- What are the core values of the company? 
- Why were those core values chosen?

- How do you communicate your core values to your customers?

- Do you think your customers perceive your core values through the product?

The subsequent questions focused on the relation of perceived quality attributes regarding each of the core values (quality, safety, and environmental care):

- I know that you have several product attributes that define your brand and products. Can you explain what an attribute is and how you work with attributes?

- Which attributes are more important?

- Which attributes are the most communicative to the customers?

During the interviews, additional questions were occasionally asked to further explore topics and determine perceived quality attributes more clearly. For example, "Can you give any examples of how your core values are represented by product attributes?" or "Do you believe that your customers can interpret your core values through the products' attributes?"

The interviews were voice-recorded and later transcribed to text. The text was coded and analysed using NVivo qualitative data analysis software, a program designed to assist with qualitative data analysis. The material was organised into topic areas (or 'nodes'):

(1) core values, i.e., general information regarding brand core values;

(2) quality, i.e., data related to the quality as a core value;

(3) safety, i.e., data related to the safety as a core value;

(4) environment, i.e., data related to the environmental care as a core value;

(5) $P Q$ attributes, i.e., perceived quality attributes associated with the representation of the core values; and

(6) communication strategies, i.e., a phenomenon derived from the interviews.

To ensure reliability data for coding and to minimise discrepancy, analysis of the content of all interviews was performed by two independent coders. The process of data Unitising (Krippendorff, 2013) was conducted with the identification of content sections relevant to the purpose of this study - identification of perceived quality attributes that represent core values.

To measure observed agreement between coders (see Figure 4) we calculated Kappa - agreement coefficients (Cohen, 1960). The coding procedure included two phases (workshops): 1) an initial phase involving coding strategy discussion, followed by 2) a focused phase where the data was synthesised and integrated to the nodes.

According to Krippendorff's criteria of an acceptable level of reliability, variables with reliabilities above 0.800 are reliable. Henceforth, we believe that with the Kappa value of 0.9 good agreement was achieved among the involved coders during data analysis. 
Figure 4 Coder agreement values across the defined nodes, represented in NVivo software

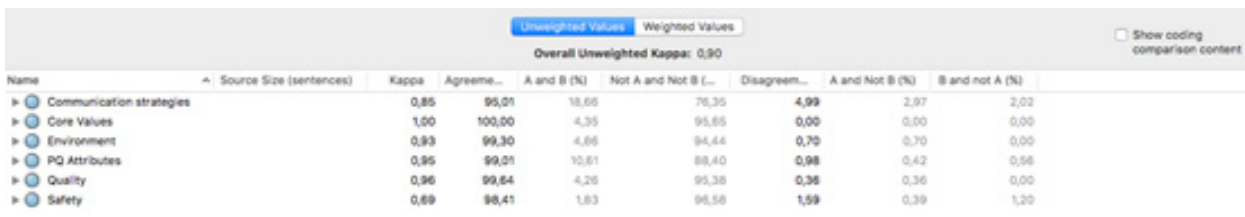

\subsubsection{Results from the interviews}

The interviews provided valuable information regarding branding, communicative strategies, and ways of setting requirements to fulfil core value-related needs. The data show commonalities and discrepancies between VCG and VT, and the results were used to formulate lists of product attributes that correspond to each of the common core values. These lists, shown in Table 1, were used in the subsequent survey of car and truck drivers.

Table 1 Summary of key attributes from the interviews

\begin{tabular}{|c|c|c|c|}
\hline & Quality & Safety & Environmental care \\
\hline \multirow{7}{*}{ VCG } & "Luxury experience" & Innovative active safety & Minimising carbon \\
\hline & Fit and finish & systems & dioxide emissions \\
\hline & Split lines & Accident prevention & Hybrid vehicles \\
\hline & $\begin{array}{l}\text { NVH (noise, vibration } \\
\text { and harshness) }\end{array}$ & & Drive-E powertrain \\
\hline & Craftsmanship & & \\
\hline & Touch and feel & & \\
\hline & $\begin{array}{l}\text { HMI (human machine } \\
\text { interface) }\end{array}$ & & \\
\hline \multirow{9}{*}{ VT } & Durability & Reliability & Fuel efficiency \\
\hline & Reliability & Maintainability & Exterior design \\
\hline & Robustness & Navigation systems & Low emissions \\
\hline & Gaps and flush & Active and passive safety & Hybrid vehicles \\
\hline & Fit and finish & & \\
\hline & Functionality & & \\
\hline & Comfort & & \\
\hline & $\begin{array}{l}\text { HMI (human machine } \\
\text { interface) }\end{array}$ & & \\
\hline & Uptime & & \\
\hline
\end{tabular}

\subsubsection{Volvo Car Group (VCG) interviews}

VCG currently has three major pillars that form requirements for current and future products: created around people, contemporary luxury experience, and strength in every sense. The interviews revealed the professional opinion that all players in the premium car segment had achieved a certain level of quality, so quality is no longer a product 
differentiator. VCG's strategy regarding quality is to set a "luxury experience" through exterior design as well as through the interior, split lines, fit and finish, NVH (noise, vibration, and harshness), and craftsmanship. Some professionals stated that there is a need for changing means of communication to avoid technocratic information delivery regarding vehicle characteristics and capabilities. However, as already mentioned in the background section, communicating quality is a challenging task, and one interviewee cited that attempts to communicate quality in the premium vehicle segment could sometimes be interpreted by customers as a lack of quality. This can be explained by the customer's expectation of high quality in the premium segment as a prerequisite.

Another important factor is the customisation of the car for different markets, as perceived quality is understood differently in different markets. Although VCG is a global company, Sweden is an important segment, where it achieves a market share of more than 22\%. Volvo is perceived as a mass brand in Sweden, while in the rest of the world Volvo is positioned as a premium brand. This creates a conflict for designers, according to one of the interviewees. Today, Volvo produces simplified versions of its cars for the Swedish market, while the global products are more advanced to fit the highquality segment. Therefore, there is a need to understand how to communicate Scandinavian design and values to the rest of the world more effectively. Many of these critical decisions are solely based on the designer's experience.

Finding 1 - Endorsed brands and feature clustering communicates product quality: In order to improve perceived quality, VCG has created endorsed brands (Aaker and Joachimsthaler, 2000) and clustering. Individual features are difficult to communicate, so VCG combines them into clusters. One example that displays such an approach is the sound system. VCG has several sound packages that range from basic to premium, together with well-known sound system brands such as Bowers and Wilkins and Harman/Kardon. These brands already have their own strong reputations on the market, which can raise the perceived quality of Volvo accordingly. Another example is a collaboration with Philips regarding interior lighting design in the vehicles. There is an additional idea to frame different features together that appeal to particular target audiences as a vehicle made to fulfil their purposes and support their everyday activities, such as sport or winter packages. With clustering in mind, VCG has created a number of its own endorsed brands, such as City Safety (auto brake technology), BLIS (Blind Spot Information System), Sensus (HMI functionality), and Drive-E (engine architecture) powertrain. There is a strong belief that such an approach can simplify customer understanding of technology and increase perceived quality.

One important and emerging factor in perceived quality is the Human Machine Interface (HMI). A well-designed HMI can help avoid driver distractions and reduce accidents. VCG sees further development of HMI systems as another opportunity to differentiate their products in the market.

Finding 2 - Shift towards communication of active safety systems and assistive approach: Volvo cars traditionally have a strong reputation for safety, and safety is not surprisingly one of the company's core values. One VCG professional claimed: "We could stop talking about safety and customers will still have that perception." However, the reputation is based on passive safety factors, such as the chassis and structure, and today's market emphasises active safety features, such as stability control and danger detection systems. This new approach to active safety is to prevent accidents from occurring rather than only developing systems that help minimise injuries to occupants when an accident happens. VCG is changing the dialogue from "it protects you" to "it 
makes you an even better driver." The goal is to communicate safety in a more supportive way. Implementation of VCG's safety strategy involves a shift towards innovative active safety systems, such as City Safety, pedestrian detection, and lane departure warning.

Finding 3 - A key component of environmental care communication is conformance to specifications with low running costs: Environmental care is most prominently represented by the Drive-E powertrain family, which is known for low emissions. VCG's strategy for communicating environmental care focuses mainly on reducing carbon dioxide emissions. Based on EU legislation that sets mandatory emission reductions, the company seeks to meet customer demand by offering vehicles that emit less than 100 grams of carbon dioxide per kilometre $\left(\mathrm{CO}_{2} / \mathrm{km}\right)$ driven. Through such specifications, the company aims to communicate "premium vehicle with low emissions," and as a consequence also communicate low running costs. Moreover, VCG is developing advanced plug-in hybrid vehicles that communicate environmental care while still delivering comprehensive performance.

\subsubsection{Volvo Trucks (VT) interviews}

VT communicates five primary attributes to its customers. These attributes represent the company's core values: uptime, innovation, care, fuel efficiency and driver environment. VT takes a different approach than VCG, since customer demands are more concrete and the relationship is most often business-to-business.

Finding 4 - Quality in trucks is represented mainly by reliability and robustness: The VT interviewees mentioned that customers today are highly aware of many of the mechanical and technological properties of trucks. Quality in trucks on a physical level is represented by durability and reliability. The interviews reveal that "quality impression" is what is perceived by the customer regarding quality. Quality impression contains robustness, where the most important part is absence of free play in the parts of the truck. This also includes gaps and flush, with emphasis on consistent gaps between parts, surface fit and finish represented by homogeneity among the parts and colours, as well as functionality and comfort impression, which includes proper sound feedback that suits the operation. In a similar way to VCG, VT has created endorsed brands to increase perceived quality of its products and technologies. Professionals say that one of the biggest challenges for truck companies today is to offer a premium service, and uptime and aftersales service are of high importance to their customers. The HMI also plays a significant role in perceived quality for trucks; the dashboard must have a reliable interface and should work even if the customer is wearing work gloves. Indicators of the major truck functions should be visible, and VT accumulates information that is important for a driver in what they call the "driver information display".

Finding 5 - Safety in trucks is communicated with security and emotions: As VT's communication strategy translates quality into benefits; the company seeks to communicate safety in connection with emotions. Professionals believe that customers want to feel secure inside a truck. From their perspective, the most important features after safety in a truck are reliability and maintainability. Navigation systems as part of the HMI also play a role in fulfilling safety demands, by minimising driver distraction. These features, along with active and passive safety systems, contribute to a communication image of VT with safety as one of its core values. 
Finding 6 - A communication platform that helps owners highlight environmental friendliness of their vehicles: Environmental care is a core value that is challenging to transmit through truck design. VT created an environmental communication platform that aims to market the environmental friendliness of its trucks, focusing on emissions, energy, and climate. VT's product range includes a methane-diesel truck that features lower emissions and fuel consumption in comparison to regular diesel-powered trucks. It is believed that this truck is perceived by the customers as environmentally friendly, and by owning such a truck customers contribute effort to society and environmental care. An interview with a Swedish Volvo truck fleet owner confirmed that he felt this way about the methane-diesel trucks in his fleet. Fleet owners want to show their customers that they use environmentally friendly vehicles.

Professionals from VT have found that the best ways to communicate that visually are a slightly different design of the cabin and colours that represent environmental care. Environmental care is still not highly perceived in trucks, but there appears to be high demand from the customer side in Sweden (and perhaps elsewhere). There is also a demand for hybrid trucks operating in the city. The study revealed that professionals are aware of these issues and are continuously looking for improvements in these areas. Data analysis of the interviews shows that VT has a trend toward clustering its technical packages in the same way as VCG. Regarding quality, the trend toward simplification has focused on developing customer services and customer relations.

\subsection{Summary of the VCG and VT interviews}

The interview study highlighted communication strategies and perceived quality attributes associated with the core values of these two companies from the professionals' point of view. As described above, VCG and VT professionals avoid "technocratic" forms of product presentation with too many technical details. Instead, there is a change to "clusters" or packages that are understandable to customers without a technical background. This leads to the creation of endorsed brands around vehicle manufacturers and, in some cases, collaboration with third-party brands with strong reputations.

A summary of the main features discussed in both sets of interviews is shown in Table 1. A list of the more specific product attributes that communicate each of the companies' core values is provided in Table 2 .

Table 2 List of attributes and affiliated companies and core values

\begin{tabular}{|c|c|c|c|c|c|c|c|}
\hline \multirow[b]{2}{*}{$A b b r$} & \multirow[b]{2}{*}{ Attribute } & \multicolumn{3}{|c|}{ Cars } & \multicolumn{3}{|c|}{ Trucks } \\
\hline & & $Q$ & $S$ & $E$ & $Q$ & $S$ & $E$ \\
\hline Abr & Active braking & & & & & $\mathrm{x}$ & \\
\hline Acc & Acceleration time & $\mathrm{x}$ & & & $\mathrm{x}$ & & \\
\hline $\mathrm{ACr}$ & Adaptive cruise control system & & & & & $\mathrm{x}$ & $\mathrm{x}$ \\
\hline Aer & Aerodynamic exterior shape & & & $\mathrm{x}$ & $\mathrm{x}$ & & $\mathrm{x}$ \\
\hline Air & Air freshness & $\mathrm{x}$ & & & $\mathrm{x}$ & & \\
\hline $\mathrm{BrN}$ & Volvo brand name / Brand of truck & $\mathrm{x}$ & $\mathrm{x}$ & $\mathrm{x}$ & $\mathrm{x}$ & $\mathrm{x}$ & $\mathrm{x}$ \\
\hline BSD & Blind spot detection system & & $\mathrm{x}$ & & & $\mathrm{x}$ & \\
\hline $\mathrm{CO} 2$ & Carbon dioxide emissions & & & $\mathrm{x}$ & & & $\mathrm{x}$ \\
\hline Com & Comfort & $\mathrm{x}$ & & & $\mathrm{x}$ & & \\
\hline
\end{tabular}


Table 2 List of attributes and affiliated companies and core values (continued)

\begin{tabular}{|c|c|c|c|c|c|c|c|}
\hline \multirow[b]{2}{*}{$A b b r$} & \multirow[b]{2}{*}{ Attribute } & \multicolumn{3}{|c|}{ Cars } & \multicolumn{3}{|c|}{ Trucks } \\
\hline & & $Q$ & $S$ & $E$ & $Q$ & $S$ & $E$ \\
\hline $\mathrm{CSF}$ & Colours and surface finish & $\mathrm{x}$ & & & $\mathrm{x}$ & & \\
\hline $\mathrm{CSS}$ & $\begin{array}{l}\text { City safety system (low speed crash } \\
\text { avoidance) }\end{array}$ & & $\mathrm{x}$ & & & & \\
\hline Dig & Digital speedometer & $\mathrm{x}$ & $\mathrm{x}$ & & & & \\
\hline DnM & Durability and maintainability & $\mathrm{x}$ & $\mathrm{x}$ & $\mathrm{x}$ & $\mathrm{x}$ & $\mathrm{x}$ & $\mathrm{x}$ \\
\hline DrE & Drive-E (efficient engine technology) & & & $\mathrm{x}$ & & & \\
\hline DST & Dynamic stability and traction control & & $\mathrm{x}$ & & & & \\
\hline EIP & Energy absorbing instrument panel & & & & & $\mathrm{x}$ & \\
\hline $\mathrm{EnN}$ & Engine noise & & & & $\mathrm{x}$ & & \\
\hline ESP & Electronic stability program (ESP) & & & & & $\mathrm{x}$ & \\
\hline ESW & Energy-absorbing steering wheel & & & & & $\mathrm{x}$ & \\
\hline Exh & Exhaust & & & & & & $\mathrm{x}$ \\
\hline $\mathrm{ExN}$ & External noise & & & & & & $\mathrm{x}$ \\
\hline Fen & Functionality & & & & $\mathrm{x}$ & & \\
\hline FCW & Forward collision warning & & & & & $\mathrm{x}$ & \\
\hline FDB & Feedback on driving behaviour & & & & & & $\mathrm{x}$ \\
\hline FPD & Free from production defects & $\mathrm{x}$ & & & & & \\
\hline $\mathrm{FuC}$ & Fuel consumption & & & $\mathrm{x}$ & & & $\mathrm{x}$ \\
\hline $\mathrm{GpE}$ & $\begin{array}{l}\text { Uniformity and size of gaps between } \\
\text { exterior parts (such as doors and hood) }\end{array}$ & $\mathrm{x}$ & & & $\mathrm{x}$ & & \\
\hline GpI & $\begin{array}{l}\text { Uniformity and size of gaps between interior } \\
\text { parts (such as on instrument panel) }\end{array}$ & $\mathrm{x}$ & & & $\mathrm{x}$ & & \\
\hline HAS & Home safe and approach lighting & & $\mathrm{x}$ & & & & \\
\hline ICA & Inflatable curtain airbags & & $\mathrm{x}$ & & & & \\
\hline IIS & $\begin{array}{l}\text { Intuitiveness of infotainment system } \\
\text { (e.g., navigation and stereo controls) }\end{array}$ & $\mathrm{x}$ & & & & & \\
\hline InL & Interior lighting & $\mathrm{x}$ & & & & & \\
\hline $\mathrm{LCS}$ & Lane change support & & & & & $\mathrm{x}$ & \\
\hline LDB & Locally designed and built & & & $\mathrm{x}$ & & & \\
\hline LDW & Lane departure warning system & & $\mathrm{x}$ & & & $\mathrm{x}$ & \\
\hline LFW & Low-friction wheels & & & $\mathrm{x}$ & & & \\
\hline $\log$ & $\begin{array}{l}\text { Feature-specific logos (e.g., hybrid, methane } \\
\text { diesel, stereo brand name) }\end{array}$ & $\mathrm{x}$ & & & $\mathrm{x}$ & & $\mathrm{x}$ \\
\hline Lwt & Light weight & & & $\mathrm{x}$ & & & $\mathrm{x}$ \\
\hline MEx & $\begin{array}{l}\text { Minimalistic exterior "look" (not too many } \\
\text { lines or details) }\end{array}$ & $\mathrm{x}$ & & & & & \\
\hline Mir & Mirrors & & & & & $\mathrm{x}$ & \\
\hline NLI & Noises inside the car (e.g., squeaks, rattles) & $\mathrm{x}$ & & & & & \\
\hline
\end{tabular}


Table 2 List of attributes and affiliated companies and core values (continued)

\begin{tabular}{|c|c|c|c|c|c|c|c|}
\hline \multirow[b]{2}{*}{$A b b r$} & \multirow[b]{2}{*}{ Attribute } & \multicolumn{3}{|c|}{ Cars } & \multicolumn{3}{|c|}{ Trucks } \\
\hline & & $Q$ & $S$ & $E$ & $Q$ & $S$ & $E$ \\
\hline NLO & $\begin{array}{l}\text { Noise level inside the car (e.g., from wind, } \\
\text { engine) }\end{array}$ & $\mathrm{x}$ & & & & & \\
\hline ORC & Off-road capability & $\mathrm{x}$ & $\mathrm{x}$ & & & & \\
\hline PBS & Presence of blind spots/visibility & & $\mathrm{x}$ & & & $\mathrm{x}$ & \\
\hline PNM & $\begin{array}{l}\text { Presence of natural materials (like real wood } \\
\text { and leather) }\end{array}$ & $\mathrm{x}$ & & & & & \\
\hline PPS & Pedestrian protection system & & $\mathrm{x}$ & & & & \\
\hline PRM & Presence of real materials (e.g., chrome, Al.) & & & & $\mathrm{x}$ & & \\
\hline Rec & Recyclability & & & $\mathrm{x}$ & & & \\
\hline Rel & Reliability & $\mathrm{x}$ & $\mathrm{x}$ & & $\mathrm{x}$ & $\mathrm{x}$ & $\mathrm{X}$ \\
\hline Res & Resale or recyclability & & & & & & $\mathrm{x}$ \\
\hline Rmy & Roominess & $\mathrm{x}$ & & & & & \\
\hline $\mathrm{SC}$ & Seat comfort & $\mathrm{x}$ & & & & & \\
\hline SDL & Sound of door latch & & & & $\mathrm{x}$ & & \\
\hline SEA & Stylish external appearance & $\mathrm{x}$ & & & $\mathrm{x}$ & & \\
\hline Ser & Customer care and service quality & & & & $\mathrm{x}$ & & \\
\hline SIP & Side impact protection system & & $\mathrm{x}$ & & & & \\
\hline SRM & Scratch resistance of materials & $\mathrm{x}$ & & & & & \\
\hline Size & Size of car & & $\mathrm{x}$ & & & & \\
\hline ToC & $\begin{array}{l}\text { Tightness of controls (e.g., steering wheel, } \\
\text { gear shifter, pedals) }\end{array}$ & $\mathrm{x}$ & & & $\mathrm{x}$ & & \\
\hline TPM & Tire pressure monitoring & & & & & $\mathrm{x}$ & \\
\hline TSB & Three-point safety belt with electronic lock & & & & & $\mathrm{x}$ & \\
\hline Wgt & Weight of car & & $\mathrm{x}$ & & & & \\
\hline WRW & Water repellent windshield & & $\mathrm{x}$ & & & & \\
\hline
\end{tabular}

Note: $\quad$ Core values: $Q=$ quality, $S=$ safety, $E=$ environmental care

\section{Driver study}

The specific product attributes described during the interviews with the professionals were compiled into comprehensive lists of car and truck attributes that correspond to each core value, shown in Table 2. In essence, these attributes are the outcome of the content analysis of the interviews (see Sub-section 3.1), compiled in a form suitable for the survey design. Using these lists, two surveys were developed to understand how drivers of cars and trucks perceive and value these core values and attributes. The surveys were conducted online, with a Swedish sample group recruited from a panel through a market research firm. Responses were collected from 67 Volvo car drivers and 18 current or former truck drivers, 14 of whom had most recently driven a Volvo truck. After asking several qualification questions to ensure that respondents were comfortable 
with an English survey, lived in Sweden, and drove a Volvo car or a semi-trailer truck (of any brand), both surveys began by asking free-response questions about what descriptive words came to mind when the drivers thought about their car/truck and each of the core values (quality, safety, and environmental care). There was also a question asking them to select as many of the following words that they associated with their car/truck: fun, environmentally friendly, safe, elegant, dynamic, sophisticated, rigid, high-quality, and versatile.

This was followed by a set of semantic-differential questions to understand whether certain attributes were deemed important for each of the core values. These questions were needed to anchor the ordinal rankings that would subsequently be found in the maximum-difference scaling (MaxDiff) section. This can reveal whether one attribute is more important than another, but not whether the attribute is minimally or highly important. Three attributes were presented for each core value. These were chosen because of their perceived importance by the professional interviewees, and the attributes differed between cars and trucks. These attributes are listed in Table 3, and an example of a set of semantic-differential questions is shown in Figure 5.

Table 3 Attributes used in semantic-differential questions

\begin{tabular}{|c|c|c|c|}
\hline & Quality & Safety & Environmental care \\
\hline Cars & $\begin{array}{ll}\text { - } & \text { "Feeling" when } \\
\text { sitting inside } \\
\text { - } & \text { Acceleration time } \\
\text { - } & \text { Stylish exterior }\end{array}$ & $\begin{array}{ll}\text { - } & \text { Pedestrian protection } \\
\text { system }\end{array}$ & $\begin{array}{ll}\text { - } & \text { Fuel consumption } \\
\text { - } & \text { Carbon dioxide } \\
\text { emissions }\end{array}$ \\
\hline Trucks & $\begin{array}{l}\text { - } \text { Reliability/uptime } \\
\text { - } \quad \text { Sound of door } \\
\text { latch } \\
\text { - } \quad \text { Comfort }\end{array}$ & $\begin{array}{ll}\text { - } & \text { Visibility } \\
\text { - } & \text { Lane keeping support } \\
\text { - } & \text { Tire pressure } \\
\text { monitoring }\end{array}$ & $\begin{array}{ll}\text { - } & \text { Fuel consumption } \\
\text { - } & \text { Lightweight materials } \\
\text { - } & \text { Exhaust }\end{array}$ \\
\hline
\end{tabular}

Figure 5 Semantic-differential questions corresponding to cars and quality

How important are each of the following attributes in a quality car?

\begin{tabular}{|c|c|c|c|c|c|}
\hline & $\begin{array}{c}1 \\
\text { (Not at all } \\
\text { important) }\end{array}$ & 2 & 3 & 4 & $\begin{array}{l}5 \\
\text { (Highest } \\
\text { priority) }\end{array}$ \\
\hline $\begin{array}{l}\text { "Feeling" when } \\
\text { sitting inside }\end{array}$ & $\bigcirc$ & 0 & 0 & 0 & 0 \\
\hline Acceleration time & $\mathrm{O}$ & $\mathrm{O}$ & $\mathrm{O}$ & $\mathrm{O}$ & $\mathrm{O}$ \\
\hline Stylish exterior & $\bigcirc$ & $\bigcirc$ & $\bigcirc$ & O & $\mathrm{O}$ \\
\hline
\end{tabular}

Following each set of semantic-differential questions, a set of MaxDiff choice tasks was given for the attributes related to each of the core values. This was done to ascertain a rank ordering of the attributes for each respondent. An example MaxDiff choice task is shown in Figure 6. 
Figure 6 Example MaxDiff choice task for Volvo car drivers regarding quality

Please consider how important different features are when selecting a high-quality car. Considering only these 6 features, which is the Most Important and which is the Least Important? (1 of 12)

\begin{tabular}{|c|c|c|}
\hline $\begin{array}{c}\text { Most } \\
\text { Important }\end{array}$ & $\begin{array}{c}\text { Least } \\
\text { Important }\end{array}$ \\
\hline$\bigcirc$ & Uniformity and size of gaps between exterior parts (such as doors and hood) & \\
\hline & Reliability & \\
\hline & Minimalistic exterior "look" (not too many lines or details) & \\
\hline & Free from production defects & \\
\hline & Colors and surface finish & $\bigcirc$ \\
\hline & Tightness of controls (e.g., steering wheel, gear shifter, pedals) & $\bigcirc$ \\
\hline
\end{tabular}

Click the 'Next' button to continue..

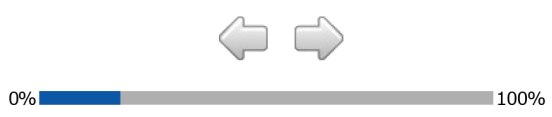

In each MaxDiff choice task the respondent was required to select one "most important" feature and one "least important" feature. The ensuing choice tasks presented the respondent with different permutations of the attributes listed in Table 2, and the number of choice tasks in each series was adjusted to the number of attributes. The permutations and numbers of questions were automated using the Sawtooth Software package (Orme, 2005).

\subsection{Volvo car drivers}

The survey first asked the drivers to select words that they associated with their Volvos from a list of 9 words. This was intended to identify if the core values in general were getting through in the designs. Of the 67 drivers, the responses showed that 50 thought of their Volvos as "high-quality", 61 as "safe", and 20 as "environmentally friendly". This indicates that the first two core values are being communicated to the customers significantly more effectively than the last one. This was not a surprising result given that the professionals themselves focused less on environmental care than they did on quality and safety in the semi-structured interviews.

Next, the survey focused on each of the core values sequentially, first asking for an importance rating for three attributes in each category, and then performing a MaxDiff ranking exercise comprised of 6-12 questions each (depending on the total number of attributes to be rank-ordered). The importance ratings were evaluated on a semanticdifferential scale, where an evaluation of 1 means "not important at all" and a score of 5 means the "highest priority". The average results from these questions are shown as insets in Figures 7, 8 and 9. Since all of these averages were above the middle option (3), we can believe that the rankings for these attributes in the MaxDiff exercise should reflect attributes that are important for evaluating products with respect to the three core values. 
Figure 7 Importance of the quality attributes for Volvo car and trucks drivers (see Table 2 for abbreviation key)

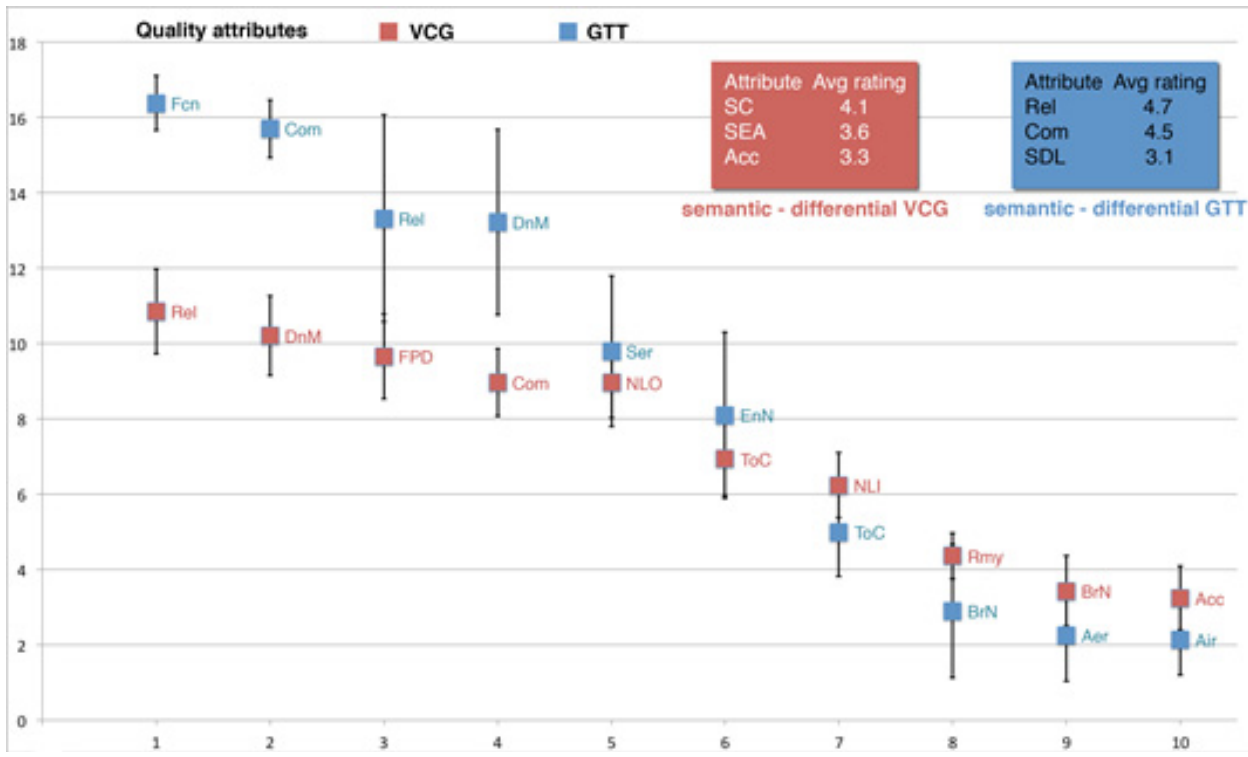

Figure 8 Importance of the safety attributes for Volvo car and trucks drivers (see Table 2 for abbreviation key)

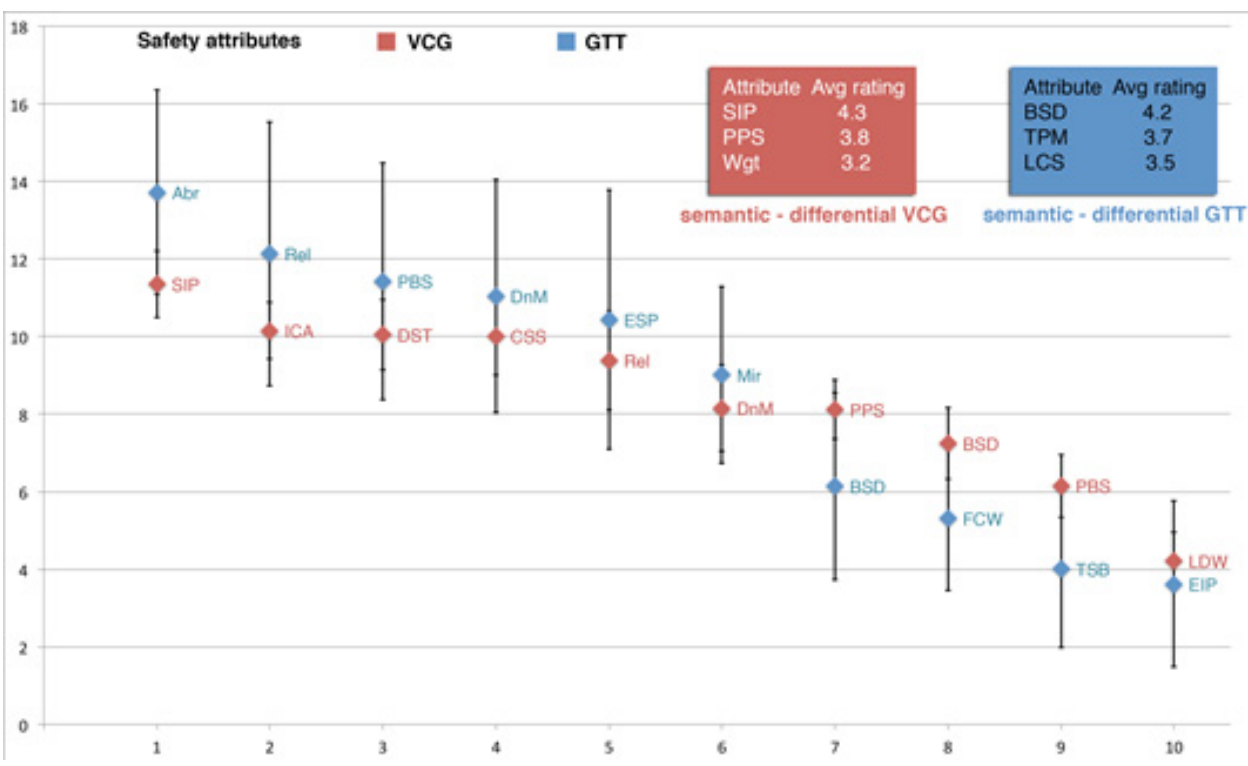


Figure 9 Importance of the environmental care attributes for Volvo car and trucks drivers (see Table 2 for abbreviation key)

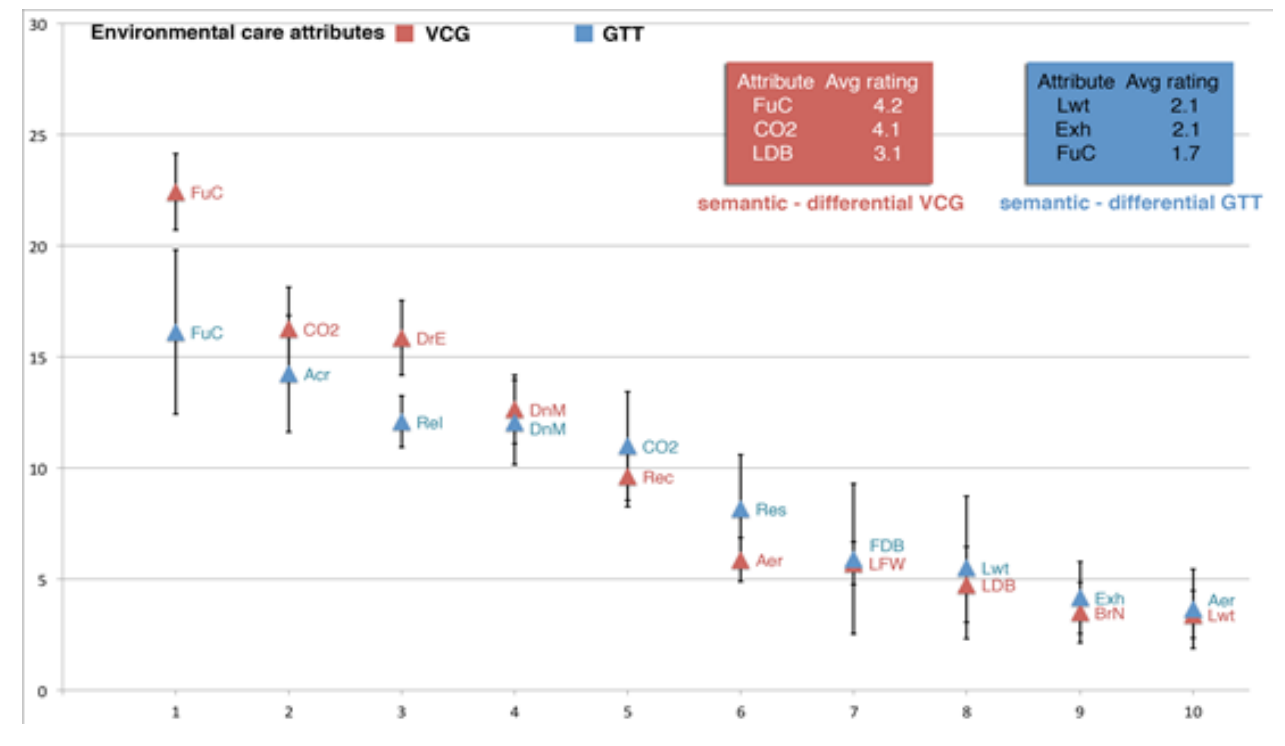

The results from the MaxDiff questions presented to car owners are summarised in Figures 7,8 and 9, and show the top ten average attributes that are most important to customers regarding each core value.

\subsection{Truck drivers}

A similar survey was conducted with a group of 18 truck drivers using the truck-specific attributes from Table 2 . These attributes were deemed important to truck design based on the interviews with professionals at VT. They were first asked the same association questions as the car owners, and of the 14 Volvo truck drivers 10 thought of their truck as "high quality", 9 as "safe", and 5 as "environmentally-friendly". This is similar to the proportions stated by the Volvo car drivers.

The semantic differential scale importance ratings and MaxDiff rank-order results for the truck drivers are also shown in Figures 7, 8, and 9. In contrast to the car drivers' importance ratings, where the three core values seemed to be valued as approximately equally important, Figure 9 shows how the truck drivers valued environmental carerelated attributes much lower than quality and safety attributes. In fact, fuel consumption is rated close to "not at all important" for truck drivers, whereas car drivers placed the same attribute closer to a "highest priority". This is possibly because car drivers are typically responsible for paying for the fuel that is consumed, whereas truck drivers may not have that concern.

One counterintuitive result from this study is that while fuel consumption receives a lower rating from the truck drivers than lightweight materials and exhaust on the semantic-differential scale, fuel consumption is ranked higher than the other two in the MaxDiff ranking. This is most likely a result of how the respondents interpreted the two forms of questions, as well as perhaps the low reliability of the MaxDiff method with small sample sizes. Similarly, the higher spreads in the GTT results are likely also due to the smaller sample size. 


\section{Discussion}

The semi-structured interviews with VCG and VT professionals revealed several interesting trends. Both companies position themselves as premium brands. In this segment of the market they believe that quality has increased to the point that it is no longer a differentiator among products or brands in the premium segment. Professionals also believe that Volvo's reputation for safety is highly perceived by the customers, and the quantitative survey confirms this. Both companies have the common goal to be leaders in this area. Today, VCG and VT are seeking to achieve this through the implementation of active safety packages in cars and trucks. However, there are significant differences in their definitions of quality and environmental care. The main quality issues for VCG are "zero-defects", customisation, and the use of endorsed brands. VT communicates quality primarily through reliability and durability. Another key point is environmental care, which VCG communicates through the endorsed brand Drive-E and the concept of a "premium vehicle with low emissions". VT communicates environmental care by focusing on emissions, energy, and climate within the framework of an Environmental care platform.

It appears that the nature of designing and assessing for high-perceived quality is complex, and professionals must know which aspects to focus their efforts on to meet the quality demands of their customers. The interview studies revealed that exterior design plays a significant role in communicating quality to both car and truck customers. In the case of VCG this is expressed as Scandinavian design, and for VT it is part of the innovation platform they communicate. However, the level of importance of exterior design for perceived quality remains unclear.

Difficulties in objectively prioritising product attributes can influence a company's communication strategies and potentially reduce perceived quality. This can negatively affect the perception of brand core values by customers. Interviewees from both companies clearly stated the need for robust methods of perceived quality assessment to aid in their attribute design prioritisation.

The rapidly increasing development of HMI systems in both cars and trucks will be expanded and developed even further in the future, and its role is expected to change from a supportive feature to an actively perceived quality component. The professionals interviewed believe that touchscreens in vehicle HMI systems will become more prominent in cars and trucks and help to unify the infotainment and communication systems of the vehicle. Again, the means for assessing the importance of HMI systems remain subjective at present.

This study has shown how industry professionals attempt to communicate core values and technical details to their potential customers. Interviews revealed how engineers are seeking to shift from a technocratic way of presentation into an emotional appeal that meets customer needs. VCG expresses such emotions through perceived quality attributes led by three pillars: contemporary luxury experience, strength in every sense, and created around people. VT communicates five major attributes to its customers: uptime, innovation, after sale care, fuel efficiency and driver environment (see Figure 10). 
Figure 10 Key perceived quality attributes that are communicated to customers by professionals

\section{Emotions to communicate}

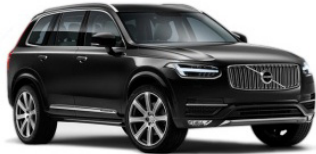

Created around people

Strength in every sense

Contemprorary luxury experience

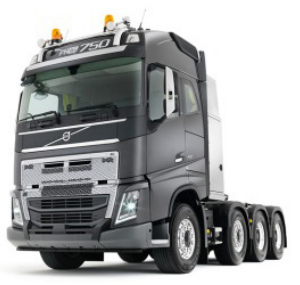

Uptime

Innovation

Fuel efficiency

After sale care

Driver environment

VT professionals revealed that they expend significant effort on improving the quality impression of their trucks. Like VCG, they seek an emotional response from customers by creating sub-brands and using feature clusters. Yet the challenge lies in which vehicle attributes design engineers should focus on to better match customer perceptions of quality. While there is no established method or tool for objective justification of perceived quality requirements, the present study shows how this can be done using a combination of exploratory research methods. A better understanding of perceived quality attributes will benefit the abilities of professionals to truly understand customer needs and demands.

The quantitative survey of drivers confirmed some of the trends highlighted by professionals, while also providing important insights into how customers value different attributes and assess vehicle quality, safety, and environmental care. For both driver segments, reliability and durability/maintainability were in the top six in every category they appeared in, showing the importance of these characteristics for all of the core values. This contrasts with the discussions with professionals, who did not stress the importance of such attributes but instead focused on functions and user experience.

Some of the key differences between the perceptions of VCG professionals and drivers include uniformity among the parts, gap and flush, and surface finish. This likely relates to the high quality among all players in the premium segment of the market, as customers have grown to expect visibly flawless vehicles from this segment. As a result, the customer perceives quality as a given feature. In a similar way, VT perceives very 
low customer attention to the exterior lines, gaps, sounds and lightweight materials used in trucks. Overall, such results can also be explained by a "quality perception gap" phenomenon that exists between manufacturers and customers (Steenkamp, 1990); with significant differences in beliefs regarding product quality between these two groups.

It should be noted that the results of this study are limited to two Swedish automotive manufacturers under the Volvo brand, and further work would be necessary to extend these findings to other companies or industries. Similar studies with other automotive companies in the premium and non-premium segments could reveal more generalisable results for the automotive industry. To advance the designer perspective, compiling knowledge not only from senior-level professionals but also from mid-range engineers and designers could help to improve the general understanding of product attributes and how they are designed. On the consumer side there are opportunities to further investigate the importance of the perceived quality attributes to customers, perhaps using different types of stated-choice or revealed-choice methods through surveys or experiments with human subjects. Extensions of this work in other industries can support the development of improved general design practices for reconciling the perceptions of values between designers and consumers.

\section{Conclusions}

This study has revealed current trends regarding the visions of Volvo professionals of their core values, and has demonstrated how customers also perceive and prioritise those values and the attributes through which they are expressed. Key discrepancies have been found and discussed regarding their implications for communication and perception differences among professionals and customers. This understanding helps to reduce the gap between the perceptions of professionals and customers, which can lead to improved product development for customer value and sales in these markets. Although Volvo has the same three core values in both companies - quality, safety, and environmental care the results show that these values are communicated in different ways for the two different markets of cars and trucks. The systematic approach presented in this paper to elicit these preferences can serve as a model for future studies that seek to understand how to better communicate core values in different markets.

\section{Acknowledgements}

We would like to thank the six professionals from Volvo Car Group and Volvo Trucks for their time and thoughtful responses during the interviews. This work carried out at the Wingquist Laboratory VINN Excellence Centre within the Area of Advance - Production at the Chalmers University of Technology, in Gothenburg, Sweden, was supported by the Swedish Governmental Agency for Innovation Systems (VINNOVA). That support is gratefully acknowledged. 


\section{References}

Aaker, D.A. and Joachimsthaler, E. (2000) 'The brand relationship spectrum: the key to the brand architecture challenge', California Management Review, Vol. 42, No. 4, pp.8-23.

Balmer, J.M. (2013) 'Corporate heritage, corporate heritage marketing, and total corporate heritage communications: what are they? What of them?', Corporate Communications: An International Journal, Vol. 18, No. 3, pp.290-326.

Beniger, J.R. (1990) 'Who are the most important theorists of communication?', Communication Research, Chicago, Vol. 17, No. 5, pp.698-715.

Berlyne, D.E. (1974) Studies in the New Experimental Aesthetics: Steps Toward an Objective Psychology of Aesthetic Appreciation, Hemisphere, Oxford, England.

Bloch, P.H. (1995) 'Seeking the ideal form: product design and consumer response', The Journal of Marketing, pp.16-29.

Burnap, A., Hartley, J., Pan, Y., Gonzalez, R. and Papalambros, P.Y. (2015) 'Balancing design freedom and brand recognition in the evolution of automotive brand styling', Proceedings of the ASME International Design Engineering Technical Conferences and Computers and Information in Engineering Conference, pp.V007T06A047-V007T06A047.

Cachia, M. and Millward, L. (2011) 'The telephone medium and semi-structured interviews: a complementary fit', Qualitative Research in Organizations and Management: An International Journal, Vol. 6, No. 3, pp.265-277.

Christozov, D., Chukova, S. and Mateev, P. (2009) 'Informing processes, risks, evaluation of the risk of misinforming', Foundations of Informing Science, pp.323-356.

Cohen, J. (1960) 'Kappa: coefficient of concordance', Educational Psychological Measurement, Vol. 20, pp.37-46.

Crilly, N., Maier, A.M. and Clarkson, P.J. (2008) 'Representing artefacts as media: modelling the relationship between designer intent and consumer experience', International Journal of Design, Vol. 2, No. 3, pp.15-27.

Crilly, N., Moultrie, J. and Clarkson, P.J. (2004) 'Seeing things: consumer response to the visual domain in product design', Design Studies, Vol. 25, No. 6, pp.547-577.

Eckert, C., Bertoluci, G. and Yannou, B. (2014) 'Handling subjective product properties in engineering, food and fashion', Proceedings of the International Design Conference, pp.791-800.

Forslund, K. and Söderberg, R. (2007) 'Categories of visual quality cues', Proceedings of the ASME International Design Engineering Technical Conferences and Computers and Information in Engineering Conference, pp.881-889.

Huertas-Leyva, P., Quattelbaum, B., Solaz, J. and Schmitt, R. (2011) 'Evaluation of perceived product quality for the integration in automotive industry supply chain', 13th EAEC, pp.1-10.

Keller, K.L. and Lehmann, D.R. (2003) 'How do brands create value?', Marketing Management, Vol. 12, No. 3, pp.26-31.

Koffka, K. (1935) Principles of Gestalt Psychology, International Library of Psychology, Philosophy and Scientific Method.

Krippendorff, K. (1986) Information Theory: Structural Models for Qualitative Data, Vol. 62, Sage.

Krippendorff, K. (2009) 'Four (in) determinabilities, not one', in Ciprut, J.V. (ed.): Indeterminacy: The Mapped, the Navigable, and the Uncharted, MIT Press, Cambridge, MA, pp.315-344.

Krippendorff, K. (2013) Content analysis: An Introduction to its Methodology, 3 ed., Sage Publications. Inc., United States.

Krippendorff, K. and Butter, R. (1984) 'Product semantics: exploring the symbolic qualities of form', Innovation, Vol. 3, No. 2, pp.4-9.

Liem, A., Abidin, S. and Warell, A. (2009) 'Designers' perceptions of typical characteristics of form treatment in automobile styling', Proceedings of the 5th International Workshop on Design and Semantics of Form and Movement, DesForm, pp.144-155. 
Louviere, J.J. (1993) 'The best-worst or maximum difference measurement model: Applications to behavioral research in marketing', Proceedings of The American Marketing Association's Behavioral Research Conference, Phoenix, Arizona.

Magidson, J., Thomas, D. and Vermunt, J.K. (2009) 'A new model for the fusion of maxdiff scaling and ratings data', Proceedings of the Sawtooth Software Conference, pp.83-103.

Marley, A.A. and Louviere, J.J. (2005) 'Some probabilistic models of best, worst, and best-worst choices', Journal of Mathematical Psychology, Vol. 49, No. 6, pp.464-480.

Monö, R.G., Knight, M. and Monö, R. (1997) Design for Product Understanding: The Aesthetics of Design from a Semiotic Approach, 1st ed., Skogs Boktryckeri, Liber.

Muller, W. (2001) Order and Meaning in Design, Purdue University Press, Boom Koninklijke Uitgevers.

Nagamachi, M. (2002) 'Kansei engineering as a powerful consumer-oriented technology for product development', Applied Ergonomics, Vol. 33, No. 3, pp.289-294.

Norman, D.A. (2013) The Design of Everyday Things, Revised and expanded edition, Basic Books, Perseus Books Group, New York.

O'Shaughnessy, J. (1992) Explaining Buyer Behavior: Central Concepts and Philosophy of Science Issues, Oxford University Press, USA.

Orme, B. (2005) Sawtooth Software Research Paper Series, MaxDiff System Technical Paper. Available online at: http://www.sawtoothsoftware.com

Rindell, A., Santos, F.P. and De Lima, A.P. (2015) 'Two sides of a coin: connecting corporate brand heritage to consumers' corporate image heritage', Journal of Brand Management, Vol. 22, No. 5, pp.467-484.

Robinson, M.V. (2000) Perceived Quality (No. 2000-01-C030), SAE Technical Paper, Convergence Transportation Electronics Association, USA.

Schmitt, R. and Quattelbaum, B. (2009) Enthusing Perceived Product Quality-A Concept for the Distribution of Sensorial Perception Information. Available online at: http://www.eoq. org/fileadmin/user_upload/Documents/Congress_proceedings/Turkey_2010/Proceedings/ B5_2._Enthusing_Perceived_Product_QualityRobert_Schmitt.pdf

Shannon, C.E. (1948a) 'A Mathematical Theory of Communication', Bell System Technical Journal, Vol. 27, No. 3, pp.379-423.

Shannon, C.E. (1948b) 'A Mathematical Theory of Communication', Bell System Technical Journal, Vol. 27, No. 4, pp.623-656.

Steenkamp, J-B.E. (1990) 'Conceptual model of the quality perception process', Journal of Business Research, Vol. 21, No. 4, pp.309-333.

Striegel, S.S. and Zielinski, D. (2018) 'Perceived quality of the split-line design and quality', DS92: Proceedings of the 15th International Design Conference (DESIGN'18), pp.453-464.

Stylidis, K., Rossi, M., Wickman, C. and Söderberg, R. (2016) 'The communication strategies and customer's requirements definition at the early design stages: an empirical study on Italian luxury automotive brands', Procedia CIRP, Vol. 50, pp.553-558.

Urde, M. (2009) 'Uncovering the corporate brand's core values', Management Decision, Vol. 47, No. 4, pp.616-638. Available online at: http://doi.org/10.1108/00251740910959459

Urde, M., Greyser, S.A. and Balmer, J.M. (2007) 'Corporate brands with a heritage', Journal of Brand Management, Vol. 15, No. 1, pp.4-19.

Vihma, S. (1995) Products as Representations: A Semiotic and Aesthetic Study of Design Products, Vol. 14, University of Art and Design, Helsinki.

Warell, A.V. (2003) Design syntactics: A functional approach to visual product form theory, models, and methods, Chalmers Tekniska Hogskola.

Yumer, M.E., Chaudhuri, S., Hodgins, J.K. and Kara, L.B. (2015) 'Semantic shape editing using deformation handles', ACM Transactions on Graphics (TOG), Vol. 34, No. 4. Doi: $10.1145 / 2766908$. 